\title{
Neue Behandlungsmöglichkeit gegen tödliche Pilzinfektionen
}

Forscher des IMBA (Institut für Molekulare Biotechnologie) und der Max F. Perutz Laboratories (MFPL) der MedUni Wien und Universität Wien haben einen neuen Mechanismus entdeckt, der es ermöglichen könnte, lebensbedrohliche Pilzinfektionen zu therapieren: Wird das Enzym CBL-B blockiert, verstärkt dies die Immunabwehr gegen den Pilzerreger Candida albicans. Wurde im Tiermodell CBL-B „ausgeschaltet", dann konnten die körpereigenen Abwehrkräfte aktiviert und eine invasive, oft tödlich verlaufende, Infektion abgewehrt werden.

Jeder Vierte leidet im Laufe seines Lebens unter unangenehmen Infektionen der Haut oder Schleimhaut; Pilzinfektionen fordern jährlich rund 1,5 Millionen Menschenleben. Ein Befall des einzelligen Hefepilzes Candida albicans verläuft meist harmlos und lässt sich gut behandeln. Erkennt ein geschwächtes Immunsystem den Erreger allerdings nicht rechtzeitig, breitet sich der Pilz im ganzen Körper aus und kann eine fungale Sepsis sowie massive Organschäden auslösen. Solche invasiven Infektionen enden in etwa 40\% Prozent der Fälle tödlich.

\) Eine Infektion mit dem häufigsten Hefepilz Candida albicans kann im geschwächten Zustand schnell lebensbedrohlich werden

Im Klinikalltag spielen Pilzinfektionen bei Menschen, deren Immun-

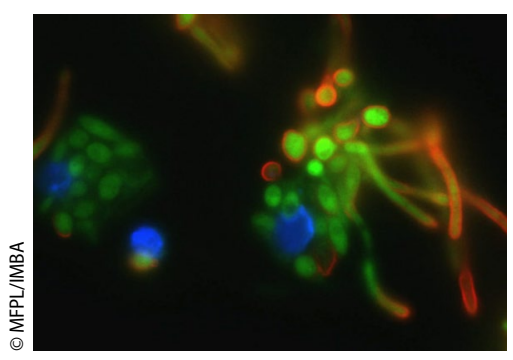

Abb. 1 - Immunabwehr in Nahaufnahme: Candida albicans (in grün) wird von der dendritischen Zelle (in blau) gefressen. Eine andere dendritische Zelle wird jedoch vom Hefepilz getötet, indem seine Pilzfäden (in rot) deren Zellmembran durchstoßen system geschwächt ist, eine immer größere Rolle. Längere Aufenthalte in Krankenhäusern, aber auch viele neuen Behandlungsmethoden wie etwa Organtransplantationen oder Tumortherapien, sind häufig mit einer kurz- bis langfristigen Schwächung oder gar Schädigung des Immunsystems verbunden. Eine Infektion mit dem häufigsten Hefepilz Candida albicans kann im geschwächten Zustand schnell lebensbedrohlich werden. Zusätzlich zu einer schwierigen Diagnose mangelt es bisher an effektiven antifungalen Therapiemöglichkeiten, um Infektionen in diesem fortgeschrittenen Stadium bekämpfen zu können.

\section{Immunantwort: Den Keim im Keim ersticken}

Wiener Wissenschafter haben nun entschlüsselt, wie sich das Immunsystem erfolgreich gegen eine Invasion von Candida albicans zur Wehr setzen kann: Die Molekularbiologen Dr. Gerald Wirnsberger und Florian Zwolanek aus den Arbeitsgruppen von Dr. Josef Penninger (IMBA) und Dr. Karl Kuchler (MFPL) konnten nachweisen, dass das Enzym CBL-B und ein Signalüberträger namens SYK eine besondere Rolle bei der Immunantwort gegen Candida spielen [1]. SYK arbeitet mit dem Immunrezeptor an der Zelloberfläche und leitet das Signal für die gezielte Abwehr gegen den Pilzerreger weiter, während CBL-B die Signalübertragung für die Immunantwort bremst und schließlich ganz abschaltet, indem es SYK zerstört.
In einem nächsten Schritt entwickelten die Forscher ein neuartiges Inhibitor-Protein, um CBL-B bei Mäusen gezielt zu blockieren. Eine invasive Candida Infektion konnte dadurch erfolgreich abgewehrt werden (- Abb. 1), während Mäuse, bei denen CBL-B aktiv war, innerhalb kurzer Zeit der systemischen Candida-Infektion erlagen. Die Ergebnisse der Studie wurden in Nature Medicine publiziert und könnten den Weg für eine neue Therapie gegen invasive Pilzinfektionen ebnen.

„Unsere Forschung ist ein erster Meilenstein zu einer völlig neuen Art der Behandlung gegen Candida albicans: Erstmals können wir die Immunantwort, die durch CBL-B moduliert wird, gezielt lenken. Diese neuartige Therapiemethode könnte sich als klinisch sehr erfolgreich herausstellen, vor allem in Kombination mit bereits existierenden Therapiemethoden, bei denen nur das Wachstum der Pilze blockiert werden kann", äußerte sich Kuchler zu den Ergebnissen der Arbeit.

\section{Literatur \\ 1. G. Wirnsberger, F. Zwolanek et al (2016) Inhibition of CBLB protects from lethal Can- dida albicans sepsis. Nat Med. doi: 10.1038/ nm.4134}

hautnah 2016 · 15:57

DOI 10.1007/s12326-016-0203-7

Online publiziert: 18. August 2016

C) Springer-Verlag Wien 2016
Quelle: IMBA -

Institut für Molekulare Biotechnologie $\mathrm{GmbH}$ 